\title{
In vitro Screening of Multifunctional Growth Stimulating Rhizobacteria Using Zea mays $\mathrm{L}$.
}

\author{
Sabiha Habib, Ambreen Ahmed* \\ Department of Botany, University of the Punjab, Quaid-e-Azam Campus, \\ Lahore 54590, Pakistan
}

Received: 5 January 2021

Accepted: 27 April 2021

\begin{abstract}
Present study highlights an organic scheme to achieve ameliorated growth of plants with enhanced nutritional status using plant growth promoting rhizobacteria (PGPR). Bacteria were in vitro screened for multifarious growth stimulatory traits including auxin production, ACC-deaminase activity, nitrogen fixation and ammonification, cyanide production and mineral solubilization. These traits are considered as the hallmarks for bacterial interaction with plants. Four efficient isolates Enterobacter sp. (A5C), Exiguobacterium sp. (A13G), Tr1 and Tr2 were selected on the basis of these traits and further applied on PGPR treated plant assay. Results revealed that all bacterial treatments significantly improved the growth parameters. Isolates Enterobacter sp. (A5C) and Tr1 tended to elevate chlorophyll 'a' upto 203.1 and $110.4 \%$ over control, chlorophyll ' $b$ ' was enhanced by 185.5 and $91.1 \%$ over control with application of Enterobacter sp. (A5C) and Exiguobacterium sp. (A13G) while isolates $\operatorname{Tr} 2$ and $\operatorname{Tr} 1$ tremendously increased carotenoid content upto 307.3 and $235.3 \%$ respectively, over control. Soluble sugar and free aminoacid content was increased up to 66 and $75.6 \%$ respectively, when inoculation was done with isolate $\operatorname{Tr} 2$. Similarly, isolate $\operatorname{Tr} 1$ caused 35.1, 385.4 and 109.4\% increase in protein, phenolic and total alkaloid content respectively, when compared with control. Concerning these significant enhancements in physio-chemical traits of Zea mays plants, PGPR can be used as bioinoculants in agricultural systems for organic treatment to get maximum plant productivity in terms of their nutritional status and biochemistry which can help us to minimize input of synthetic chemicals for growth improvement thus saving the environment from increased soil and water pollution.
\end{abstract}

Keywords: PGPR, rhizobacteria, auxin, ACC-deaminase, HCN, chlorophyll, protein, aminoacid, Zea mays L. 


\section{Introduction}

Bacteria are actually the microengineers of the soils. About all ecosystem amenities are linked with bacteria including agricultural production, safeguarding the nutrient sequestration and soil health. Soil matrix is a key to determine the variety and kind of bacteria that reside in soil. Functional traits of bacteria are versatile and still considered as black box which should be deeply focused to analyze these kind of soil engineers [1]. The plant growth promoting rhizobacteria (PGPR) could be a better alternative to other physio-chemical means to get maximum plant productivity as bacterial application is environmentally benign, cost-effective and easy to use method in agricultural system [2]. Bacteria were reported for their high heterogeneity, not only for growth stimulation of plants but also evident for providing protection from phytopathogens as biocontrol agents and defend plants from various biotic and abiotic stress [3].

Plant growth promoting rhizobacteria (PGPR) reside in plant rhizosphere and are symbiotically involved in developing plant-bacterial interactions. These kinds of bacterial communities possess plethora of growth stimulatory mechanisms that entail growth regulation by increasing protein maintenance, metabolic and defense responses of plants as environmental stabilizers $[4,5]$. Majority of the rhizospheric bacterial community of the plants exhibits the ability to produce IAA which has been implicated in virtually all aspects of plant growth and development including the production of longer roots with increased number of root hairs and lateral roots which are involved in the nutrient uptake. Also, IAA modulates division and differentiation of the cells enlargement $[6,7]$. These bacteria may also cope with the excess ethylene stress in plants by exhibiting ACC-deaminase activity. This enzyme is responsible for the cleavage of plant ethylene precursor, ACC, into ammonia and $\alpha$-ketobutyrate. By decreasing ACC levels in plants, ACC deaminase-producing bacteria decrease plant ethylene levels which when present in high concentrations can lead to plant growth inhibition or even death [8]. Also, bacteria release ammonia which could be a virtuous alternative to ammonium nitrate fertilizers. The study of Majeed et al. [9] demonstrated the role of bacterial synthesized hydrocyanic acid $(\mathrm{HCN})$ that exhibits antagonistic role against pathogenic organisms. PGPR are also involved in mineral solubilization and hydrolyze the unavailable forms of minerals into available ones to make them available for plants' uptake. Phosphate solubilizing bacteria (PSB) provide free phosphate to the plants and this solubilization occurs due to acidification of soil medium owing to the release of organic acids from bacteria that act as chelators for metal ions and form soluble complexes [10]. Similarly, Zinc solubilizing bacteria (ZSB) act as natural zinc reservoirs in plant rhizosphere in order to lessen the contribution of inorganic Zinc fertilizers [11].
Studies revealed that PGPR modulate the biosynthesis of secondary metabolites by signifying their role in overall plant growth. These metabolites enable the soil to become enriched with nutrients by solubilizing them or making them available for plant uptake such as phenols, flavonoids and alkaloids [12]. It is of utmost importance to investigate various growth promoting traits of PGPR in detail so that it will easy to suggest the type of isolate for particular plant and soil type for growth improvement [13]. The present study is aimed at the isolation of rhizospheric bacteria and their screening for multifarious plant growth promoting traits under in vitro conditions and to use these bacteria as bioinoculants to evaluate the growth response of Zea mays L. plants.

\section{Experimental Procedures}

\section{Bacterial Isolation and in vitro Screening}

Hundred bacterial strains were isolated from the rhizosphere of wheat, maize and tomato plants collected from the agricultural lands of Lahore, Pakistan. Besides, four already isolated and identified bacterial strains were also used in the current study i.e., Bacillus sp. (AAL1), Cronobacter sp. (AL2), Enterobacter sp. (A5C) and Exiguobacterium sp. (A13G). These strains were previously identified via 16S RNA sequencing by Ahmed and Hasnain [14]. All isolates were initially tested for various growth stimulatory traits and after their screening, most efficient bacteria were then used for plant growth experiment.

\section{Expression Profiling of PGPR Attributes}

\section{In vitro Auxin Biosynthesis}

Auxin production of isolates was observed following Habib et al. [15]. Bacterial cultures prepared in L-broth media with supplementation of $1 \%$ tryptophan were centrifuged and supernatant was treated with Salkowski reagent (1:2). Appearance of pink color indicated the presence of auxin. Absorbance of auxin producing isolates was recorded at $535 \mathrm{~nm}$. The amount of auxin was determined by using the standard curve.

\section{Bacterial ACC-Deaminase Activity}

ACC-deaminase activity of isolates was detected following Saini and Khanna [16] using DF-salt minimal growth media amended with $3 \mathrm{mM}$ ACC by spot inoculation method. Positive and negative controls were taken with and without $\left(\mathrm{NH}_{4}\right)_{2} \mathrm{SO}_{4}$. Isolates grown well on ACC plates were selected for quantitative analysis which was done using liquid DF-minimal media with optical density taken at $600 \mathrm{~nm}$ after five days of incubation. 


\section{Nitrogen Fixation and Ammonification}

Bacterial isolates were screened for nitrogen fixing ability qualitatively by in vitro plate assay using nitrogen-free bromothymol blue media ( $\mathrm{Nfb}$ ) following Goswami et al. [17]. Ammonia production was evaluated by nesslerization of isolates. Concisely, isolates grown in peptone broth were centrifuged and $1 \mathrm{ml}$ of supernatant was added in $1 \mathrm{ml}$ of Nessler reagent. Appearance of reddish brown color was an indication of ammonia production. Positive strains were examined quantitatively by addition of sterile distilled water upto $10 \mathrm{ml}$ following detection of optical density at $450 \mathrm{~nm}$. Ammonia concentration of isolates was estimated by standard curve of ammonium sulphate.

\section{Hydrocyanic acid (HCN) Production Assay}

HCN production of bacteria was detected following Marques et al. [18] by the color change of sterile filter paper soaked in $2 \%$ sodium carbonate in $0.5 \%$ picric acid solution placed over bacterial cultures which were spread on nutrient agar plates supplemented with $4.4 \mathrm{~g}$ of Glycine/L. Orange to red color indicated the cyanogenic response of bacteria. Quantitatively, each isolate was inoculated in respective growth media and a strip of sterile filter paper was hanged in test tube. After incubation for seven days, brownish color was developed on strips which were then soaked in $5 \mathrm{ml}$ of sterile water for $15 \mathrm{~min}$ and absorbance was recorded at $625 \mathrm{~nm}$.

\section{Mineral Solubilization}

Isolates were evaluated for phosphate and zinc solubilization qualitatively following Tirry et al. [19] and Khanghahi et al. [11] respectively. Phosphate solubilizing potential was detected using NBRIP media containing tricalcium phosphate as insoluble phosphorous source following incubation for 14 days while in vitro zinc solubilization assessment was determined using tris-minimal media containing zinc oxide as insoluble zinc source by spot inoculation method following incubation for seven days. Diameter of halo zone and solubilization index for phosphate and zinc solubilization assay was calculated and analyzed.

\section{Plant Growth Assay}

Four most efficient isolates [Enterobacter sp. (A5C), Exiguobacterium sp. (A13G), Tr1 and Tr2] were selected for plant growth studies on the basis of their multiple plant growth promoting traits. Certified seeds of Zea mays L. (var. DK-6714) were procured from Punjab Seed Corporation, Lahore and were surface sterilized using $0.1 \%$ mercuric chloride. Bacterial inoculum was prepared following Habib et al. [15]. Seeds were treated with bacterial inoculum for one hour while for control treatment, seeds were treated with sterile distilled water for same period of time. Experiment was carried out in triplicates using pots containing $165 \mathrm{~g}$ of sterilized sieved soil in each pot while seven seeds were sown per pot. Pots were placed in light (10K lux, 16 hours duration) at $25 \pm 2^{\circ} \mathrm{C}$. After 24 days of growth, seedlings were removed from their respective pots and analyzed for physio-chemical traits of treated and non-treated plants.

\section{Physio-Chemical Analysis of Plants}

Morphological parameters were noted for all treatments i.e., shoot height, root length, number of leaves and fresh weight. Also, plants were analyzed for their physio-chemical traits to have an understanding of internal biochemical attributes of plants. Chlorophyll estimation was done for which pigment was extracted using $80 \%$ acetone solution and chlorophyll ' $a$ ', ' $b$ ' and carotenoid content were detected following Lichtenthaler and Wellburn [20]. Total soluble sugar content was determined following Tiwari et al. [21]. Briefly, 0.1g plant material was homogenized in $80 \%$ methanol following incubation at $70^{\circ} \mathrm{C}$ for 30 mints. Reaction mixture was prepared by adding plant extract and $5 \%$ phenol solution in $1: 1$ with addition of $1.5 \mathrm{ml}$ of $95 \%$ sulphuric acid ensuing incubation in dark for $20 \mathrm{~min}$. Absorbance for each treatment was recorded at $490 \mathrm{~nm}$ and interpreted by the standard curve of glucose. Similarly, free aminoacid content was detected following Khanna et al. [12]. For this, $0.1 \mathrm{~g}$ plant material for each treatment was homogenized in $80 \%$ alcohol and centrifuged at $2000 \mathrm{rpm}$ for $20 \mathrm{~min}$. Thereafter, $0.2 \mathrm{ml}$ of plant extract was mixed with $3.8 \mathrm{ml}$ of ninhydrin reagent following incubating on water bath at $70^{\circ} \mathrm{C}$ for $10 \mathrm{~min}$. Reaction mixture was allowed to cool till the appearance of purplish color. Optical density was noted at $570 \mathrm{~nm}$ and free aminoacid content was determined by calibrating with standard curve of leucine. Further, protein content was checked following Lowry et al. [22], for which $1 \mathrm{~g}$ pulverized plant material was mixed in $4 \mathrm{ml}$ phosphate buffer succeeding centrifugation at $10,000 \mathrm{rpm}$ for $10 \mathrm{~min}$. Then, $0.4 \mathrm{ml}$ supernatant was mixed with $2 \mathrm{ml}$ folin mixture and incubated for 15 mints at room temperature following addition of $0.2 \mathrm{ml}$ of folin ciocalteu's phenol reagent. After incubation at room temperature for $45 \mathrm{~min}$, absorbance was recorded at $750 \mathrm{~nm}$ and protein concentrations were measured from standard curve of bovine serum albumin (BSA). Treated and non-treated plants were also analyzed for secondary metabolites i.e., total phenolic content and total alkaloid content following the methods of Iqbal et al. [23] and Tabasum et al. [24] respectively. Phenolic content was detected by preparing reaction mixture containing leaf extract $(20 \mu \mathrm{l}), 1 \mathrm{~N}$ sodium carbonate $(300 \mu \mathrm{l})$, distilled water $(158 \mu \mathrm{l})$ and folin ciocalteu reagent $(100 \mu \mathrm{l})$ following incubation in dark for two hours. Absorbance was recorded at $760 \mathrm{~nm}$ and concentration was determined using standard curve of gallic acid. 
Similarly, total alkaloids were determined while taking leaf extract $(1 \mathrm{ml})$ with $2 \mathrm{~N} \mathrm{HCl}(1 \mathrm{ml})$. Filtrate was used for further analysis and mixed with bromocresol green solution and phosphate buffer in 1:1:1. Complex formed by vigorous shaking was extracted and diluted using chloroform $(10 \mathrm{ml})$ and absorbance was measured at $470 \mathrm{~nm}$. Results were inferred using standard curve of atropine.

\section{Data Analysis}

Data obtained from PGPR treated plant assay were statistically analyzed by DMR (Duncan's multiple range) test using SPSS software v.16 $(\mathrm{P}=0.05)$.

\section{Results}

\section{Expression Profiling of PGPR Attributes}

Among all bacteria tested, isolates $\operatorname{Tr} 2, \operatorname{Tr} 1$, Enterobacter sp. (A5C) and Exiguobacterium sp. (A13G) produced 319, 219, 174 and $155 \mu \mathrm{g} / \mathrm{ml}$ of auxin respectively while others were not auxin producing (Fig. 1a). Likewise, isolates $\operatorname{Tr} 1, \operatorname{Tr} 2$, Enterobacter sp. (A5C) and Exiguobacterium sp. (A13G) were capable for nitrogen fixation vis-à-vis produced 12.5, 11.9, 9.6 and 9.5 millimoles of ammonia respectively (Fig. 1b). These isolates were also good for $\mathrm{HCN}$ production which is an important characteristic of PGPR (Fig. 1c). Isolates Exiguobacterium sp. (A13G), Enterobacter sp. (A5C) and Trl exhibited 12, 12.3 and 6.6mm diameter of halo zone for phosphate solubilization respectively while using tricalcium phosphate as insoluble source of phosphorous whereas, isolate $\operatorname{Tr} 2$ showed no activity (Fig. 1d). Similarly, isolates Tr1, Enterobacter sp. (A5C), $\mathrm{Tr} 2$ and Exiguobacterium sp. (A13G) have shown $12,10.3,7.3$ and $6 \mathrm{~mm}$ diameter of halo zone for zinc solubilization respectively, in the presence of zinc oxide supporting the fact that these isolates have potential for harboring the soil with availability of phosphate and zinc containing compounds that ultimately resulted in elevated plant growth (Fig. 1e). Similarly, isolates Tr1, Tr2, Enterobacter sp. (A5C) and Exiguobacterium sp. (A13G) hold great potential for growing on minimal media supplemented with ACC as sole nitrogen source as compared to positive control (Fig. 2).

\section{Plant Growth Assay}

Four bacteria were used in order to ascertain their growth promoting potentiality over growth of Zea mays plants. It was found that isolates $\operatorname{Tr} 2$, Exiguobacterium sp. (A13G), Tr1 and Enterobacter sp. (A5C) significantly stimulated shoot height upto $39.4,37.4,36.1$ and $28.2 \%$ respectively, when compared with control treatment. Inoculation of maize seedlings with isolates Enterobacter sp. (A5C), Exiguobacterium sp. (A13G), $\operatorname{Tr} 2$ and $\operatorname{Tr} 1$ tended to enhance root length upto 19.4, $19.3,17.8$ and $17.4 \%$ respectively, over control. Similarly, it was deduced from the results that there was only $9.09 \%$ increase in number of leaves for all bacterially treated plants, in comparison with non-treated plants. Fresh weight of inoculated seedlings with isolates $\operatorname{Tr} 2$,
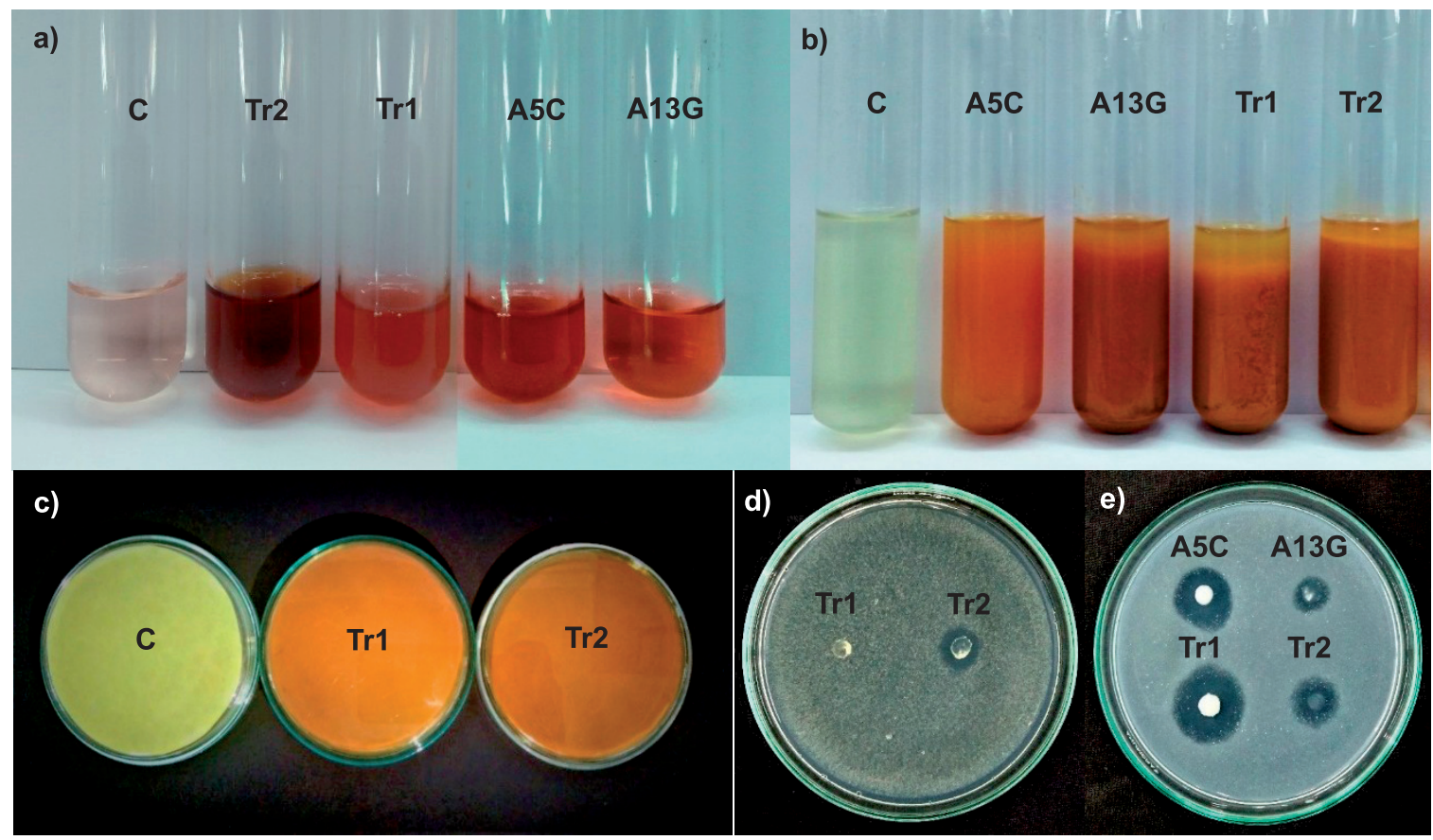

Fig. 1. Auxin production (a); Ammonia production (b); HCN production (c); Phosphate solubilizing potential (d) and Zinc solubilizing potential of bacterial isolates $(\mathrm{e})[\mathrm{C}=\mathrm{Control}, \mathrm{A} 5 \mathrm{C}=$ Enterobacter $\mathrm{sp}$., $\mathrm{A} 13 \mathrm{G}=$ Exiguobacterium $\mathrm{sp} ., \mathrm{Tr} 1$ and $\operatorname{Tr} 2-$ bacterial isolates $]$. 


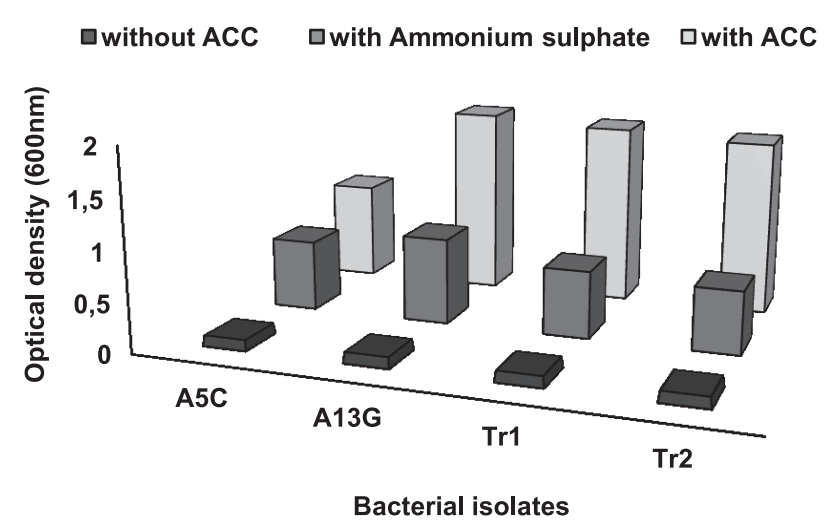

Fig. 2. ACC-deaminase activity of bacterial isolates showing bacterial growth in the absence of ACC (negative control), with ammonium sulphate (positive control) and with ACC [Enterobacter sp. (A5C), Exiguobacterium sp. (A13G), Tr1 and $\operatorname{Tr} 2=$ Bacterial strains $]$.
Exiguobacterium sp. (A13G), Tr1 and Enterobacter sp. (A5C) was also enhanced by 87.5, 87.2, 79.1 and 73.1\% respectively, over control plants (Fig. 3).

Thereafter, plants were analyzed for their internal biochemical constituents to get in-depth effects of studied PGPR on growth improvement of Zea mays plants. It was revealed from the results that bacterial application of Enterobacter sp. (A5C) and Tr1 caused tremendous increase in chlorophyll ' $\mathrm{a}$ ' content upto 203.1 and $110.4 \%$ while Exiguobacterium sp. (A13G) and $\operatorname{Tr} 2$ exhibited 44.1 and $38.4 \%$ elevation in chlorophyll 'a' respectively, as compared to chlorophyll content of untreated plants. Similarly, chlorophyll ' $b$ ' of maize seedlings was enhanced upto 185.5 and 91.1\% when treated with Enterobacter sp. (A5C) and Exiguobacterium sp. (A13G) respectively, while isolates $\operatorname{Tr} 1$ and $\operatorname{Tr} 2$ failed to enhance chlorophyll ' $b$ ' and caused decrease by 14.7 and $5.9 \%$ respectively,

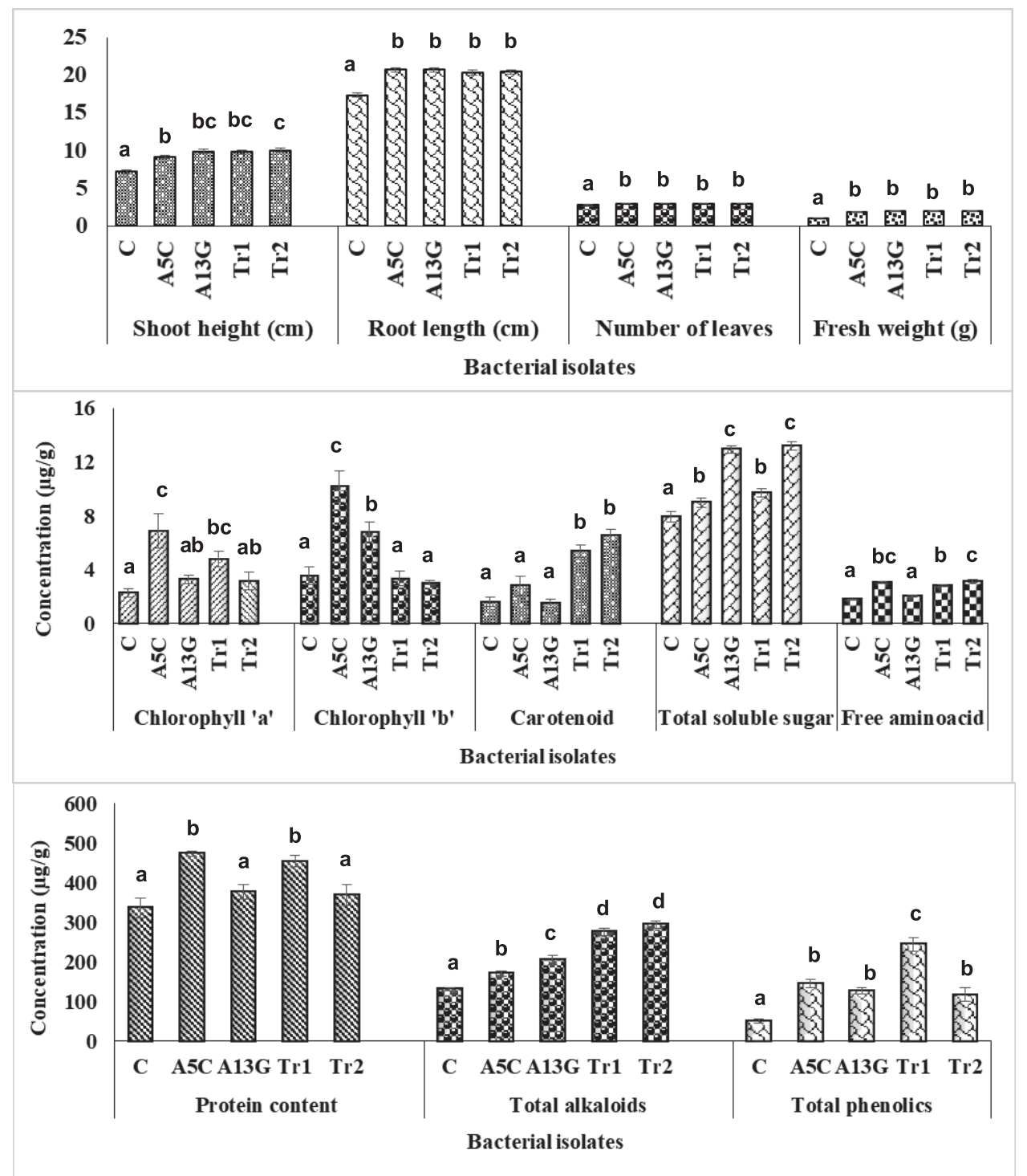

Fig. 3. Effect of bacterial inoculations on growth and biochemical attributes of Zea mays. Data represent mean of twenty four replicates. Different letters indicate significant difference between treatments using Duncan's multiple range test $(\mathrm{P}=0.05)[\mathrm{C}$ - Control; Enterobacter sp. (A5C), Exiguobacterium sp. (A13G), $\operatorname{Tr} 1$ and $\operatorname{Tr} 2=$ Bacterial strains]. 


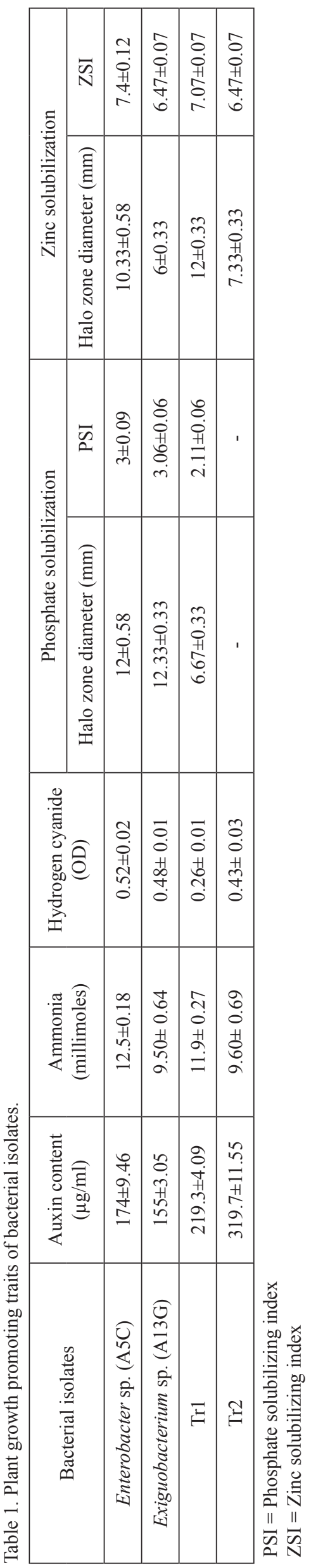

over control treatment. Likewise, carotenoid content of plants was positively influenced by isolates $\operatorname{Tr} 2$, Tr1 and Enterobacter sp. (A5C) resulting in prominent increase upto $307.3,235.3$ and $74.2 \%$ respectively, while Exiguobacterium sp. (A13G) inoculated plants showed $4.8 \%$ decrease, over control. Soluble sugar content of Tr2, Exiguobacterium sp. (A13G), Tr1 and Enterobacter sp. (A5C) inoculated plants exhibited significant increase when compared with control plants i.e., 66, 62.7, 22 and $13.2 \%$ respectively. Moreover, when plants were analyzed for their free aminoacid content, it was inferred that treatments with isolates $\operatorname{Tr} 2$, Enterobacter sp. (A5C), Tr1 and Exiguobacterium sp. (A13G) significantly improved free aminoacid content upto 75.6, 68.9, 56.2 and $14.5 \%$ respectively, over control. By the same way, 40.7, 35.1, 12.2 and 9.7\% increase in protein content was observed when plants were applied with Enterobacter sp. (A5C), Tr1, Exiguobacterium sp. (A13G) and $\operatorname{Tr} 2$ bacterial treatments respectively, in contrast with protein content of control plants. Further, to analyze the functioning of secondary metabolites in bacterially inoculated plant seedlings, total alkaloids and phenolic content was detected which revealed that isolates $\operatorname{Tr} 2, \operatorname{Tr} 1$, Exiguobacterium sp. (A13G) and Enterobacter sp. (A5C) caused prominent enhancement in total alkaloid content upto 123.3, 109.4, 55.4 and 29.9\% while bacterial supplementation for isolates $\operatorname{Trl}$, Enterobacter sp. (A5C), Exiguobacterium sp. (A13G) and $\operatorname{Tr} 2$ exhibited a tremendous increase in phenolic content i.e., $385.4,189.4,150.3$ and $132.5 \%$ respectively, contrasting with metabolites of non-treated plants (Fig. 3).

\section{Discussion}

Plant growth promoting rhizobacteria reside in soil either around or onto the surface of roots and improve growth and germination of plants by many ways. For the present study, diverse rhizospheric bacteria were isolated and were screened for multifunctional PGPR traits to analyze their behavior towards growth stimulation in Zea mays plants. Various studies report the presence of such bacteria in rhizosphere that possess PGPR traits. Fan et al. [25] conducted a study based on in vitro characterization of PGPR isolated from root zone of Robinia pseudoacaci via IAA production, ACC-deaminase synthesis and phosphate solubilization.

On basis of in vitro screening of PGPR attributes, four bacteria [Enterobacter sp. (A5C), Exiguobacterium sp. (A13G), $\operatorname{Tr} 1$ and $\operatorname{Tr} 2$ ] were used for assessing plant performance. Although, Enterobacter sp. is reported as human pathogen but it is claimed that Enterobacter spp. are known to show various plant growth promoting traits and also suppress soil-borne plant pathogens. Owing to its PGP characteristics, it is considered as potential candidate for commercially used plant growth promoter and biocontrol agent [26]. Our results indicated that bacterial isolates significantly 
improved shoot height, root length, leaves number and fresh weight of treated plants while comparing with control plants after bacterial application. Reason behind this might be bacterially synthesized auxin which is accounted for rapid cell division and multiplication resulting in enlargement of roots and shoots. Also, the most possible mechanism behind this might be the role of bacterial assisted biological nitrogen fixation and ammonia production that encourage plant to take ammonia and utilize effectively for better growth of plants. Our findings are parallel to the study of Kumari et al. [27] who stated the significant enhancements in root and shoot lengths and plant fresh weight using PGPR. Similarly, Wagi and Ahmed [28] illustrated that ACC-deaminase enzyme regulates the development of deep roots that tremendously help for water and nutrients acquisition.

PGPR exhibit multiplicity of features responsible for promoting plant growth, comprising the release of growth triggering agents and through biomineralization that not only improved the internal biology of plants but also impart prominent influence over plant biochemical attributes. Increment in chlorophyll, protein and free aminoacid content with PGPR supplementation might be due to biological fixation of nitrogen via nitrogen assimilation, since nitrogen is the main component in chlorophyll molecule and aminoacids which are building blocks of proteins. Apart from this, another suitable reason for these elevated biochemical constituents might be microbial ammonia produced by ammonification of nitrates, deamination or by degradation and decarboxylation of certain aminoacids via activity of PGPR that may lead to enhanced photosynthetic activity and protein content. Studies presented by Iqbal et al. [29] and Khanna et al. [12] are in line with our findings. Elevated level of total soluble sugar (TSS) content in bacterially inoculated plants indicated the action of PGPR that possibly tend to increase photosynthesis due to activity of ammonification and nitrogen fixation, thereby increasing sugar level of plants. Our findings were strongly supported by Tiwari et al. [21] who showed time-dependent increase in TSS via bacterial inoculation in rice seedlings comparing with noninoculated seedlings. Present work also indicated that bacterial inoculation caused marked elevation in metabolite accumulation, as assessed through enriched flavonoid and alkaloid contents quantitatively. Khanna et al. [12] also reported significant enhancements in phenolic compounds, anthocyanin, flavonoids and polyphenols in Solanum lycopersicum upon PGPR treatments. They suggested that flavonoids, benzoic acids and phenols get accumulated in plants due to enhanced phenylpropanoid metabolism that form a protective barrier around cells when exposed to any toxic agent. Thus, the current study shows growth enhancements in physio-chemical attributes of bacterially treated Zea mays plants using multitrait PGPR that assist in plant-microbe interaction.

\section{Conclusion}

In conclusion, the present study suggested that rhizosphere engineering assisted by bacteria creates a unique platform for interaction between bacteria and plants. Multifunctional PGPR showing capability of IAA synthesis, ACC-deaminase enzymes, HCN, ammonia and ability for nitrogen fixation and phosphate and zinc solubilization contributed to significant increment in Zea mays growth and biochemical attributes including chlorophyll, proteins, soluble sugars and secondary metabolites. Hence, it can be concluded that instead of using unitrait PGPR, multitrait PGPR show more enhancements in plant growth. All traits are interlocked with each other and each trait supports the other trait, thus take part to improve plant internal biology in a better way.

\section{Acknowledgement}

This work was supported by University of the Punjab, Quaid-e-Azam Campus, Lahore 54590, Pakistan.

\section{Conflict of interest}

The authors declare they have no conflict of interest.

\section{References}

1. HAMZA T.A., HUSSEIN Z., MITKU R., AYALEW P., BELAYNEH T. Isolation and Characterization of Nitrogen Fixing Bacteria from Rhizospher Soil Collected from Shell Mele Agricultural Center, Southern Ethiopia. Pearl Research Journals. 3 (7), 117, 2017.

2. OLANREWAJU O.S., GLICK B.R., BABALOLA O.O. Mechanisms of action of plant growth promoting bacteria. World J. Microb. Biot. 33 (11), 197, 2017.

3. BOUNAFFAA M., FLORIO A., LE ROUX X., JAYET P.A. Economic and environmental analysis of maize inoculation by plant growth promoting rhizobacteria in the French Rhône-Alpes region. Ecol. Econ. 146, 334, 2018.

4. KHAN N., BANO A., BABAR M.A. The stimulatory effects of plant growth promoting rhizobacteria and plant growth regulators on wheat physiology grown in sandy soil. Arch. Microbiol. 1, 2019.

5. GOUDA S., KERRY R.G., DAS G., PARAMITHIOTIS S., SHIN H.S., PATRA J.K. Revitalization of plant growth promoting rhizobacteria for sustainable development in agriculture. Microbiol. Res. 206, 131, 2018.

6. KALAM S., DAS S.N., BASU A., PODILE A.R. Population densities of indigenous Acidobacteria change in the presence of plant growth promoting rhizobacteria (PGPR) in rhizosphere. J. Basic. Microbiol. 57 (5), 376, 2017.

7. ROSIER A., MEDEIROS F.H., BAIS H.P. Defining plant growth promoting rhizobacteria molecular and biochemical networks in beneficial plant-microbe interactions. Plant Soil. 428 (1-2), 35, 2018. 
8. VEJAN P., ABDULLAH R., KHADIRAN T., ISMAIL S., NASRULHAQ BOYCE A. Role of plant growth promoting rhizobacteria in agricultural sustainability - a review. Molecules. 21 (5), 573, 2016.

9. MAJEED A., ABBASI M.K., HAMEED S., IMRAN A., RAHIM N. Isolation and characterization of plant growthpromoting rhizobacteria from wheat rhizosphere and their effect on plant growth promotion. Front. Microbiol. 6, 198, 2015.

10. KIZHAKEDATHIL M.P.J., SUBATHRA DEVI C. Rhizoshpheric bacteria isolated from the agricultural fields of Kolathur, Tamilnadu promotes plant growth in mustard plants. Biocat. Agric. Biotechnol. 16, 293, 2018.

11. KHANGHAHI M.Y., RICCIUTI P., ALLEGRETTA I., TERZANO R., CRECCHIO C. Solubilization of insoluble zinc compounds by zinc solubilizing bacteria (ZSB) and optimization of their growth conditions. Environ. Sci. Pollut. Res. 25 (26), 25862, 2018.

12. KHANNA K., JAMWAL V.L., SHARMA A., GANDHI S.G., OHRI P., BHARDWAJ R., AL-HUQAIL A.A., SIDDIQUI M.H., ALI H.M., AHMAD P. Supplementation with plant growth promoting rhizobacteria (PGPR) alleviates cadmium toxicity in Solanum lycopersicum by modulating the expression of secondary metabolites. Chemosphere. 230, 628, 2019.

13. AHMED A., HASNAIN S. Auxin-producing Bacillus sp.: Auxin quantification and effect on the growth of Solanum tuberosum. Pure Appl. Chem. 82 (1), 313, 2010.

14. AHMED A., HASNAIN S. Extraction and evaluation of Indole acetic acid from indigenous auxin-producing rhizosphere bacteria. J Anim Plant Sci. 30 (4), 1024, 2020.

15. AHMED A., HASNAIN S. Extraction and evaluation of Indole acetic acid from indigenous auxin-producing rhizosphere bacteria. J Anim Plant Sci. 30 (4), 1024, 2020.

16. HABIB S., FATIMA H., AHMED A. Comparative Analysis of Pre-Germination and Post-Germination Inoculation Treatments of Zea mays L. to Mitigate Chromium Toxicity in Cr-Contaminated Soils. Pol. J. Environ. Stud. 28 (2), 597, 2019.

17. SAINI P., KHANNA V. Preliminary Screening for ACC-deaminase Production by Plant Growth Promoting Rhizobacteria. J. Pure Appl. Microbiol. 7 (1), 573, 2013.

18. GOSWAMI D., PARMAR S., VAGHELA H., DHANDHUKIA P., THAKKER J.N. Describing Paenibacillus mucilaginosus strain N3 as an efficient plant growth promoting rhizobacteria (PGPR). Cogent Food Agric. 1 (1), 1000714, 2015.
19. MARQUES A.P., PIRES C., MOREIRA H., RANGEL A.O., CASTRO P.M. Assessment of the plant growth promotion abilities of six bacterial isolates using Zea mays as indicator plant. Soil Biol. Biochem. 42 (8), 1229, 2010.

20. TIRRY N., JOUTEY N.T., SAYEL H., KOUCHOU A., BAHAFID W., ASRI M., EL GHACHTOULI N. Screening of plant growth promoting traits in heavy metals resistant bacteria: prospects in phytoremediation. J. Genet Eng. Biotechnol. 16 (2), 613, 2018.

21. LICHTENTHALER H.K., WELLBURN A.R. Determinations of total carotenoids and chlorophylls a and b of leaf extracts in different solvents. 591, 1983.

22. TIWARI S., PRASAD V., CHAUHAN P.S., LATA C. Bacillus amyloliquefaciens confers tolerance to various abiotic stresses and modulates plant response to phytohormones through osmoprotection and gene expression regulation in rice. Front. Plant Sci. 8, 1510, 2017.

23. LOWRY O.H., RESEBROUGH N.J., FARR A.L. Protein measurement with the folin-phenol reagent. J. Biol. Chem. 193, 265, 1951.

24. IQBAL M.A., KHALID M., ZAHIR Z.A., AHMAD R. Auxin producing plant growth promoting rhizobacteria improve growth, physiology and yield of maize under saline field conditions Int. J. Agric. Biol. 18, 37, 2016.

25. TABASUM S., KHARE S., JAIN K. Spectrophotometric quantification of total phenolic, flavonoid and alkaloid contents of Abrus precatorius L. seeds. Asian J. Pharm. Clin. Res. 9 (2), 371, 2016.

26. JHA C.K., AERON A., PATEL B.V., MAHESHWARI D.K., SARAF M. Enterobacter: role in plant growth promotion. In Bacteria in agrobiology: Plant growth responses (pp. 159-182). Springer, Berlin, Heidelberg. 2011.

27. KUMARI P., MEENA M., GUPTA P., DUBEY M.K., NATH G., UPADHYAY R.S. Plant growth promoting rhizobacteria and their biopriming for growth promotion in mung bean (Vigna radiata L.) R. Wilczek). Biocat. Agric. Biotechnol. 16, 163, 2018.

28. WAGI S., AHMED A. Bacillus spp.: potent microfactories of bacterial IAA. PeerJ 7:e7258. DOI 10.7717/peerj.7258, 2019.

29. IQBAL M., WAGI S. AHMED A. Phyllospheric bacterial treatments improve growth in Helianthus annuus L. RADS J. Biol. Res. Appl. Sci. 9 (1), 35, 2018. 